
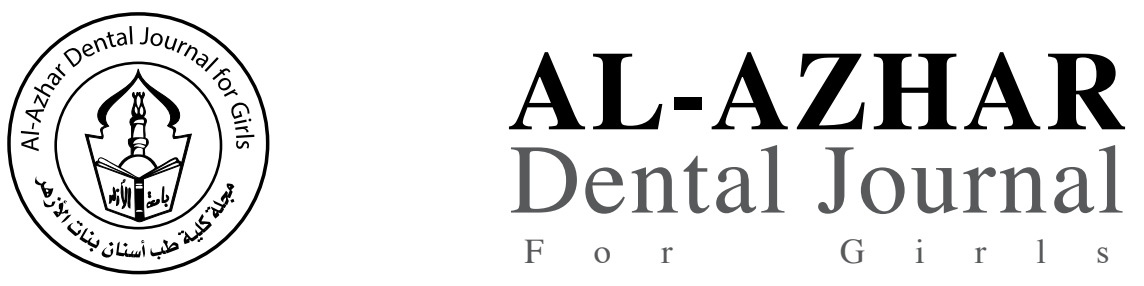

The Official Publication of The Faculty of Dental Medicine For Girls,

Al-Azhar University Cairo, Egypt.

ADJ-for Grils, Vol. 4, No. 3, July (2017) — PP. 303:309

\title{
Effects of Different Tooth-Conditioning Agents on Bond Strength of A Resin-Modified Glass-Ionomer Cement to Enamel
}

\author{
Ahmed Tharwat Hafez Ahmed Alammary(1)
}

Codex : 36/1707

dentaljournal.forgirls@yahoo.com

\begin{abstract}
The purpose of this study was directed to evaluate the effects of different tooth conditioning agents on shear bond strength of resin-modified glass- ionomer cement (Fuji III LC) to enamel as well as on dissolution of calcium ions from the enamel surfaces. Methods. The enamel surfaces of lower incisors were treated with 10 and $20 \%$ polyacrylic acid, $12 \%$ citric acid and $35 \%$ phosphoric acid for 20 s. Fuji III LC was applied to the etched enamel surfaces, and the shear bond strength of each specimen was measured using an Instron Universal Testing Instrument. The amounts of calcium ions dissolved from the treated enamel surfaces were also measured using a polarized Zeeman atomic absorptiometer. Results. In specimens pretreated with distilled water, $10 \%$ polyacrylic acid, $20 \%$ polyacrylic acid, $12 \%$ citric acid and $35 \%$ phosphoric acid, the mean values of shear bond strength were 5.5, 12.5, 15.2, 15.2 and 15.1 MPa, respectively, and the amounts of $\mathrm{Ca} 2$ dissolved from the enamel surfaces were 5.6,41.4, 88.5, 131.6 and $588.3 \mathrm{mg} / \mathrm{cm} 2$,respectively. Conclusions. The adhesion of a resin-modified glass-ionomer cement to enamel was significantly improved by the use of tooth-conditioning agents. Especially, treatments of an enamel surface with $20 \%$ polyacrylic acid results in good shear both strength and relatively small degree of enamel erosion.
\end{abstract}

\section{INTRODUCTION}

Sealing of pits and fissures has generally been accepted to have significant effects on the prevention of occlusal caries. ${ }^{1-4}$ Resin-based and glass- ionomer cements are currently used widely in clinical practice. Glass-ionomer cement is known to have the characteristic of adhering chemically to the tooth structure, ${ }^{5-7}$ and there have been many reports on the retention of glass -ionomer cement applied to pits and fissures in clinical practice. High retention rates of glass -ionomer cement have been demonstrated in clinical trials. ${ }^{3,8,9}$ McLean and Wilson ${ }^{3}$ reported $84 \%$ complete clinical retention after 1 year and $79 \%$ after 2 years.

1. Lecturer of Operative Dentistry Depatement, Faculty of Dental Medicine, Al-Azhar University (Asuit Branch) 
McKenna and Grundy ${ }^{8}$ showed a retention rate of $82.5 \%$ after 1year. Mills and Ball ${ }^{9}$ also reported a similar retention rate of $81 \%$ after 1 year and $83 \%$ after 2 years. Other investigators, ${ }^{10-14}$ however, have pointed out that a glass-ionomer cement used to cover pits and cements may not have full retention during the first 6 months to 1 year after application. Shimokobe et al. ${ }^{10}$ reported that glass -ionomer cement completely disappeared within 6 months. Boksman et al. ${ }^{11}$ reported that cement was absent in $94 \%$ of cases after 6 months. Meja're and Mjo " $\mathrm{r}^{12}$ reported that total loss of cement occurred in $61 \%$ of cases after 6-12 months and in $84 \%$ of cases after 30-36 months. Forss et al. ${ }^{13}$ and Williams et al. ${ }^{14}$ also reported very low retention rates in their 2-4 year clinical trials. Accordingly, it was suggested that glass -ionomer cement requires reapplication or replacement to maintain a complete seal of the occlusal surface. ${ }^{15}$ In all of these studies, however, the caries-preventive effect of the cement was significant. Treatment of enamel surfaces with an acid prior to cement application has not been included in the conventional procedure for the use of glass -ionomer cement. This may have been a reason for the low retention rates of glass -ionomer cements. However, there have been no reports on appropriate pretreatment of enamel surfaces when sealing pits and fissures with glass - ionomer cement.

The purpose of this study was to evaluate the effects of tooth-conditioning agents on bond strength of resin-modified glass -ionomer cement to enamel as well as on dissolution of calcium ions from the enamel surfaces.

\section{MATERIALS AND METHODS}

A total number of 55 sound non carious human extracted lower incisors, free of cracks and any developmental defects, were used in this study. The teeth washed under running tab water to remove blood and debris, scaled to remove calculus and remnants of periodontal tissues, polished with fine pumice and soft rubber cups rotating at low speed under coolant. The teeth were stored in distilled water at room temperature $\left(37 \mathrm{C}^{0}\right)$ until use. The distilled water was changed daily. The roots of the teeth were removed and the center of the labial surface of each crown was cut into a $10 \mathrm{~mm} 2 \mathrm{sec}-$ tion. The teeth were embedded in auto polymerizing polyester resin in a casting ring of $22 \mathrm{~mm}$ in diameter and $30 \mathrm{~mm}$ in height with the surface of the labial enamel parallel to the base of the molded polyester. The enamel surfaces were ground with a grinding paper disc of 180 grit (CARBIMETw; BUEHLER, Lake Bluff, IL, USA) and polished with polishing paper of 600 grit (CARBIMETw) using MINIMETw1000 (BUEHLER). The speed/force in grinding or polishing was $30 \mathrm{rpm} / 13.3 \mathrm{~N}$ for $5 \mathrm{~min}$. The specimens were then stored in distilled water at $48 \mathrm{C}$. The grounded enamel surfaces were washed with distilled water using an ultrasonic apparatus (ULTRASONICCLEANERw; SHARP,Osaka, Japan) prior to each experiment.

Table 1: Conditioning agents for pretrement of enamel.

\begin{tabular}{|l|l|l|}
\hline $\begin{array}{l}\text { Conditioning } \\
\text { Agents }\end{array}$ & Company Chief & Component \\
\hline $\begin{array}{l}\text { Dentin condition- } \\
\text { er GC Company, }\end{array}$ & $\begin{array}{l}\text { Tokyo 113 0033, } \\
\text { Japan }\end{array}$ & $\begin{array}{l}10 \% \text { polyacrylic } \\
\text { Acid }\end{array}$ \\
\hline Cavity & $\begin{array}{l}\text { conditioner GC } \\
\text { Tompany, } \\
\text { Japan } 113 \text { 0033, }\end{array}$ & $\begin{array}{l}\text { 20\% polyacrylic } \\
\text { Acid }\end{array}$ \\
\hline $\begin{array}{l}\text { BONDWELL LC } \\
\text { Conditioner }\end{array}$ & $\begin{array}{l}\text { GC Company, } \\
\text { Tokyo 113 0033, } \\
\text { Japan }\end{array}$ & $\begin{array}{l}12 \% \text { citric } \\
\text { Acid }\end{array}$ \\
\hline $\begin{array}{l}\text { Scotchbond } \\
\text { etchant }\end{array}$ & $\begin{array}{l}\text { 3M Dental } \\
\text { Products, } \\
\text { St Paul, MN } \\
\text { 55144, USA }\end{array}$ & $\begin{array}{l}35 \% \text { phosphoric } \\
\text { Acid }\end{array}$ \\
\hline
\end{tabular}




\section{Shear testing}

Preparation of the experimental surfaces of the enamel consisted of $20 \mathrm{~s}$ etching with the conditioning agents listed in Table 1 followed by $10 \mathrm{~s}$ rinsing and air-drying. A teflon tube of $4.0 \mathrm{~mm}$ in diameter and $1.5 \mathrm{~mm}$ in height was placed on the etched enamel surface and gently filled with resin modified glass -ionomer cement (Fuji III LCw; GC Corporation, Tokyo, Japan) that had been mixed according to the instructions of the manufacturer and then subjected to light illumination (New Light VLIIw; GC Corporation, Tokyo, Japan) for $30 \mathrm{~s}$ from the top of the teflon tube over a celluloid strip. The tip of the light curing unit was placed as close to the strip as possible. The intensity of the light source was $837 \mathrm{~mW} / \mathrm{cm} 2$ at the peak of wavelength. ${ }^{16}$ The teflon tube and the celluloid strip were removed after light-curing had been completed, and the rest was stored in distilled water at $37.08 \mathrm{C}$ for $24 \mathrm{~h} .{ }^{17,18}$

Each group consisted of eight samples. Thermal fatigue tests were then carried out using 500 cycles of thermal stress and the samples were kept alternately for $30 \mathrm{~s}$ in a water bath of either 5 or $558 \mathrm{C}$ in each trial. ${ }^{17,18}$ After the loading of thermal stress, Shear bond strength was measured using Universal Testing Machine (LR 5K LLOYD instruments, Ltd, Hampshire, UK) as shown in Figure(1).

The use of jig enabled a load to be applied parallel to the enamel surface at the cement -enamel interface. The blade was pulled up at a crosshead speed of $1 \mathrm{~mm} / \mathrm{min}$ (Fig. 1). All samples were tested in this way to measure their shear bond strengths..$^{17,18}$ Fractured surfaces of the samples were coated with gold, and the type of fracture was examined using an IBAS image analysis system. The percentage of remaining cement on the experimental tooth surface was estimated. The type of fracture was assessed with a modified adhesive remnant index (ARI). ${ }^{19-21}$ The ARI scale has a range of 5 to 1:5 in the case of no cement remaining on the enamel, ${ }^{4}$ in the case of less than $10 \%$ of cement remaining, 3 in the case of more than $10 \%$ but less than $90 \%$ of cement re- maining, ${ }^{2}$ in the case of more than $90 \%$ of cement remaining, and 1 in the case of all of the cement remaining on the enamel surface.

The ARI scores were also used as a more complex means of defining the site of bond failure between the enamel and the cement. Demineralized calcium ions ( $\mathrm{Ca} 2)$ measurement for demineralized $\mathrm{Ca} 2$ measurement, adhesive tape with a hole of $6.0 \mathrm{~mm}$ in diameter was attached to the enamel surface to regulate the area for conditioning. The enamel surfaces were then etched for $20 \mathrm{~s}$ using 10 $\mathrm{ml}$ of each conditioning agent (Table 1). The etching process was stopped by soaking the whole sample in $20 \mathrm{ml}$ of $1 \%$ weight lantern chloride solution.

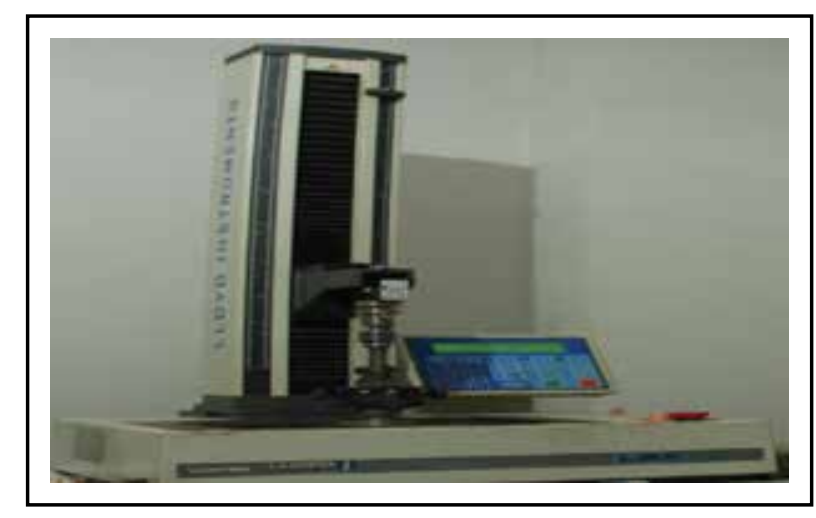

Fig. (1) Instron Universal Testing Machine (LR 5K LLOYD instruments, Ltd, Hampshire, UK).

The solution was immediately shaken for $20 \mathrm{~s}$ using an ultrasonic apparatus (SONIFIER Model 185w; Branson Sonic Power, Danbury, CT, USA) and supplemented with $2 \mathrm{ml}$ of hydrochloric acid at the final concentration of $0.1 \mathrm{~N}$ to prevent precipitation of calcium. The $4 \mathrm{rCa} 2$ concentration in the solution was measured using a polarized Zeeman atomic absorptiometer (Z-8100; HITACHI, Tokyo, Japan), and the original amount of demineralized $\mathrm{Ca} 2$ dissolved from the enamel surfaces $(\mathrm{mg} / \mathrm{cm} 2)$ was calculated. Each group consisted of three samples. Statistical analysis, The experimental data were analyzed statistically using one-way ANOVA and Fisher's PLSD. 


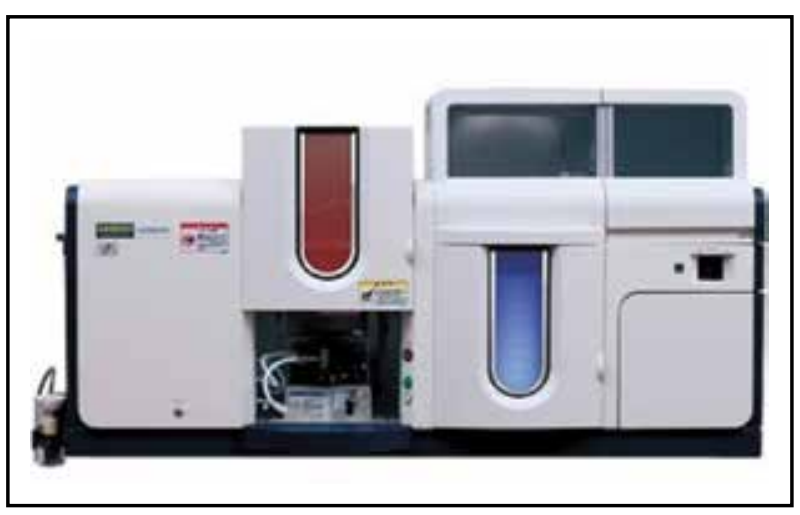

Fig. (2) Polarized Zeeman Atomic Absorption Spectrophotometer ZA3000 Series (Asuit university, Faculty of Sciences).

\section{RESULTS}

\section{Shear bond strength}

Table 2 shows the shear bond strength of each group. Pretreatment with any of the conditioning agents used in this study resulted in an increase in shear bond strength compared to that without pretreatment $(\mathrm{p}, 0.01)$. The shear bond strength of the group pretreated with Dentin Conditioner was significantly lower than those of the other groups $(\mathrm{p}, 0.01)$. No statistically significant differences were found among the other three groups (Cavity Conditioner w, BONDWELL LC Conditionerw and Scotchbond Etchantw). Adhesive residual index (ARI) The ARI scores for the five groups tested are presented in. There were no significant differences between the five groups, although there were some different distributions of ARI scores in five groups. Demineralized calcium ions (Ca21) measurement shows the results of demineralized $\mathrm{Ca} 2$ measurement. The amount of demineralized $\mathrm{Ca} 2$ in the group pretreated with deionized water was $5.6 \mathrm{mg} / \mathrm{cm} 2$. This may have been $\mathrm{Ca} 2$ that contaminated the sample solution during experimental procedures such as storing and washing. This value, however, was significantly less than the values in other groups and considered to be the baseline value for the experiment. The amounts (means standard deviations) of demineralized $\mathrm{Ca} 2$ enamel surfaces exposed to Dentin Conditioner, Cavity Conditionerw, BONDWELL LC Conditioner and Scotchbond Etchant were 41.4, $3.8,88.5,3.1,131.6,10.7$ and $588.3,28.3 \mathrm{mg} / \mathrm{cm} 2$, respectively. Statistically significant differences were found among these four groups $(p, 0.05)$.

Table (2) Shear bond strength of each group

\begin{tabular}{|l|c|}
\hline Conditioning agents & Shear bond strength (mpa) \\
\hline Distilled water & $5.5+_{-} 1.3$ \\
\hline Dentin conditioner & $12.5+_{-} 1.8$ \\
\hline Cavity conditioner & $15.2+_{-} 1.4$ \\
\hline Bondwell LC conditioner & $15.2+_{-} 1.0$ \\
\hline Scotchbond Etchant & $15.1+_{-} 1.0$ \\
\hline
\end{tabular}

\section{DISCUSSION}

Glass-ionomer cement has the characteristic of adhering chemically to the tooth structure..$^{5-7}$

It was, therefore, thought that preparation of an enamel surface prior to the cement application, such as enamel etching with phosphoric acid that is performed before the application of a resinbased cement, is not necessary for a glass -ionomer cement. However, some studies have shown that bond strength to enamel (or dentin) of a glass ionomer cement used for filling was improved by tooth conditioning with an acid. ${ }^{22-24}$ Accordingly, it is possible that bond strength to enamel of a glass ionomer cement used as a cement is also improved by surface treatment. The purpose of this study was to evaluate the effects of tooth-conditioning agents on bond strength of Fuji III LCw to enamel as well as on dissolution of calcium ions from the enamel surface. This study demonstrated that the shear bond strength of a resin-modified glass-ionomer cement to enamel increased significantly by using an acid, especially by using $20 \%$ polyacrylic acid, $12 \%$ citric acid or $35 \%$ phosphoric acid. The mean value of shear bond strength was obtained by pretreatment 
of the enamel surfaces with $20 \%$ polyacrylic acid or $12 \%$ citric acid (15.2 $\mathrm{MPa})$, while the mean value in the untreated group was only 5.5 $\mathrm{MPa}$. The increase in shear bond strength by surface treatment coincides with the results of other studies, $25-34$ though it is difficult to compare our data directly with those of other studies because of differences in the experimental designs, such as thermal fatigue testing, regulation of the size of adhesion area and the cement material used. Shear testing of Fuji III LCw, which was applied to enamel after pretreatment with conditioning agents, frequently revealed cohesive/interfacial fracture, as indicated by the ARI scores, most of which were distributed 4 or 3 . Studies by Gordan et al. ${ }^{33}$ (using Fuji Bond $\mathrm{LCw}$ with $20 \%$ polyacrylic acid) and Dewji et al. ${ }^{34}$ (using Fuji III LCw with $20 \%$ polyacrylic acid) also showed that both cohesive and interfacial fractures occurred at the interface between enamel and resinmodified glass-ionomer cement.

We also examined the dissolution of calcium ions from the enamel surfaces. The results showed that the amounts of calcium ions dissolved from enamel surfaces treated with distilled water, $10 \%$ polyacrylic acid, $20 \%$ polyacrylic acid, $12 \%$ citric acid and 35\% phosphoric acid were significantly different ( $\mathrm{p}, 0.05)$. The mean value of $5.6 \mathrm{mg} / \mathrm{cm} 2$ in specimens pretreated with distilled water was considered to be a baseline concentration of calcium ions, possibly due to contamination during the procedure of ultrasonic stirring of the specimens.

The amount of $\mathrm{Ca} 2$ dissolution in specimens treated with $20 \%$ polyacrylic acid was approxi mately two-times greater than that in specimens treated with $10 \%$ polyacrylic acid. The amount of $\mathrm{Ca} 2$ dissolution in specimens treated with $12 \%$ citric acid was significantly greater than the amounts in specimens treated with the abovementioned two agents, and the greatest amount of $\mathrm{Ca} 2$ dissolution was in specimens treated with $35 \%$ phosphoric acid.

The roughness of the enamel surface is thought to be related to micro-mechanical bond strength,$^{35}$ and it is thought that the most effective conditioning agents for adhesion, such as citric acid and phosphoric acid, dramatically alter enamel surfaces. The results of $\mathrm{Ca} 2$ dissolution indicate the degree of enamel erosion and surface roughness. However, no significant differences were found between shear bond strengths of specimens treated with $20 \%$ polyacrylic acid, $12 \%$ citric acid and $35 \%$ phosphoric acid. These findings suggest that adhesion of Fuji III LCw to enamel depends mainly on the chemical polar and ionic bond rather than on the micromechanical bond. Powis et al. ${ }^{23}$ reported that the most effective surface conditioners to improve the adhesion of a glass -ionomer cement were high-molecular-weight substances containing amultiplicity of functional groups capable of hydrogen bonding, such as polyacrylic acid, and that these substances did not greatly disrupt the enamel surfaces, ensuring effective cleaning and wetting of the surfaces. They also reported that low-molecularweight chelating agents, such as citric acid, that dissolve calciferous material and dramatically alter the surfaces were less effective. The retention rate of glass -ionomer cement is generally thought not to be high. Most studies, ${ }^{3,8,10,12-15}$ however, have shown that dental caries rarely occurred in pits and fissures sealed with glass -ionomer cement regardless of the retention rate. It is thought that the caries-preventive effect of glass -ionomer cement depends not only on retention within pits and fissures but also on fluoride release to adjacent tooth structures and the oral environment. ${ }^{13,36-38}$ Our previous study on the retention rates of resin-modified glass - ionomer cement (Fuji III LCw) ${ }^{39}$ showed full retention rates of $87.5 \%$ by clinical examination and $50 \%$ by SEM examination at 12 months and $70.3 \%$ by clinical and $9.7 \%$ by SEM at 24 months. Secondary caries was detected in only one case at 18-month recall. In that clinical trial, $10 \%$ polyacrylic acid (Dentin Conditioner w; GC, Tokyo) was used as an enamel surface-conditioning agent.

The present study, which was designed to establish a clinical procedure that would improve 
the retention rate, revealed that the use of some conditioning agents significantly increased the shear bond strength of resin-modified glass - ionomer cement to enamel. There were no differences in shear bond strengths of specimens treated with $20 \%$ polyacrylic acid (15.2 $\mathrm{MPa}), 12 \%$ citric acid (15.2 $\mathrm{MPa})$ and $35 \%$ phosphoric acid (15.1 MPa). On the other hand, the degree of $\mathrm{Ca} 2$ dissolution, i.e. the severity of enamel erosion, varied according to the conditioning agent used.

\section{CONCLUSIONS}

The purpose of this study was to evaluate the effects of tooth-conditioning agents on bond strength of resin-modified glass -ionomer cement to enamel as well as on dissolution of calcium ions from the enamel surfaces. In conclusion, polyacrylic acid is a suitable tooth conditioning agent for a resin-modified glass -ionomer cement. Treatment of an enamel surface with $20 \%$ polyacrylic acid results in good shear bond strength and relatively small degree of enamel erosion.

\section{REFERENCES}

1. Cueto EI, Buonocore MG. Sealing of pits and fissures with an adhesive resin: its use in caries prevention. Journal of the American Dental Association 2000;75:121-8.

2. Ripa LW, Cole WW. Occlusal sealing and caries prevention: results 12 months after a single application of adhesive resin. Journal of Dental Research 2002;49:171-3.

3. McLean JW, Wilson AD. Fissure sealing and filling with an adhesive glass - ionomer cement. British Dental Journal 2002;136:269-76.

4. Ripa LW. Cements revisted: an update of the effectiveness of pit-and-fissure cements. Caries Research 2003;27:77-82.

5. Smith DC. A new dental cement. British Dental Journal $2003 ; 125: 381-4$.

6. Wilson $\mathrm{AD}$, Kent BE. A new translucent cement for dentistry. The glass ionomer cement. British Dental Journal 2004;132:133-5.

7. McLean JW, Wilson AD. The clinical development of the glass-ionomer cements. I.Formulations and properties. Australian Dental Journal 1999;22:31-6.
8. Mckenna EF, Grundy GE. Glass ionomer cement fissure cements applied by operative dental auxiliaries-retention Effects of tooth-conditioning agents on bond strength of a resin-modified glass -ionome cement to enamel 17 rate after one year. Australian Dental Journal 2008;32:200 - 3.

9. Mills RW, Ball IA. A clinical trial to evaluate the retention of a silver cement-ionomer cement used as a fissure cement. Operative Dentistry 2005;18:148-54.

10. 10. Shimokobe H, Komatsu H, Kawakami S, Hirota K. Clinical evaluation of glass ionomer cement used for cement. Journal of Dental Research 2005;65:812. Abstract 780.

11. Boksman L, Gratton DR, McCutcheon E, Plotzke OB. Clinical evaluation of a glass ionomer cement as a fissure cement. Quintessence International 2010;18:707-9.

12. Meja're I, Mjo“r IA. Glass ionomer and resin-based fissure cements: a clinical study. Scandinavian Journal of Dental Research 2000;98:345-50.

13. Forss H, Saarni U-M, Seppa“ L. Comparison of glassionomer and resin-based fissure cements: a 2-year clinical trial. Community Dentistry and Oral Epidemiology 2011; $22: 21-4$.

14. Williams B, Laxton L, Holt RD, Winter GB. Fissure cements: a 4-year clinical trial comparing an experimental glass polyalkenoate cement with a bis glycidyl methacrylate resin used as fissure cements. British Dental Journal 2012;180:104-8.

15. Komatsu H, Shimokobe H, Kawakami S, Yoshimura M. Cariespreventive effect of glass ionomer cement reapplication: study presents three-year results. Journal of the American Dental Association 2014;125:543-9.

16. Ando S, Onose H. A visible light activators. Journal of Dental Engineering 2015;113:14-25.

17. International Organization for Standardization. ISO/TR 11405:1994 Dental materials-guidance on testing of adhesion to tooth structure.

18. Silo G. Bond strength testing-what does it mean? International Dental Journal 2013;43:492-8.

19. Oliver RG. The effect of different methods of bracket removal on the amount of residual adhesive. American Journal of Orthodontics and Dentofacial Orthopedics 2010; 93:196-200.

20. Bishara SE, VonWald L, Olsen ME, Laffoon JF. Effect of time on the shear bond strength of glass ionomer and composite orthodontic adhesives. American Journal of Orthodontics and Dentofacial Orthopedics 2016;116:616-20. 
21. Bishara SE, VonWald L, Laffoon JF, Jakobsen JR. Effect of changing enamel conditioner concentration on the shear bond strength of a resin-modified glass ionomer adhesive. American Journal of Orthodontics and Dentofacial Orthopedics 2000;118:311-6.

22. Hotz P, McLean JW, Sced I, Wilson AD. The bonding of glass ionomer cements to metal and tooth substrates. British Dental Journal 2012;142:41-7.

23. Powis DR, Follera ${ }^{\circ} \mathrm{T}$ T, Merson SA, Wilson AD. Improved adhesion of a glass ionomer cement to dentin and enamel. Journal of Dental Research 2010;61:1416-22.

24. Nitta Y. Effect of surface treatment on microleakage and tensile bond strength of glass polyalkenoate cement. Japanese Journal of Conservative Dentistry 2013;35: $1346-73$.

25. Burgess JO, Burkett L. Shear bond strength of four glass ionomers to enamel and dentin. Journal of Dental Research 2001;72:388.

26. Cortes O, Garcia-Godoy F, Boj JR. Bond strength of resin reinforced glass ionomer cements after enamel etching. American Journal of Dentistry 2014;6:299-301.

27. Scott K, Burgess JO, Cooley RL. Shear bond strength of glass ionomers to etched and unetched enamel. Journal of Dental Research 2012;74:106. Abstract 757.

28. Kato S, Tosaki S, Hirota K. Effect of tooth surface conditioning materials on glass ionomer bonding. Journal of Dental Research 2016;74:106. Abstract 759.

29. Attin T, Buchalla W, Hellwig E. Influence of enamel conditioning on bond strength of resin-modified glass ionomer restorative materials and polyacid-modified composites. Journal of Prosthetic Dentistry 2016;76:29-33.

30. Fritz UB, Finger W, Uno S. Resin-modified glass ionomer cements: bonding to enamel and dentin. Dental Materials 2011;12:161-6.
31. Desai M, Tyas MJ. Adhesion to enamel of light-cured poly-acid dental materials. Australian Dental Journal 2015;41:393-7.

32. Pereira PNR, Yamada T, Tei R, Tagami J. Bond strength and interface micromorphology of an improved resinmodified glass ionomer cement. American Journal of Dentistry 2016; 10:128-32.

33. Gordan VV, Boyer D, So“ derholm K-J. Enamel and dentine shear bond strength of two resin modified glass ionomers and two resin based adhesives. Journal of Dentistry 2014;26: 497-503.

34. Dewji HR, Drummond JL, Fadavi S, Punwani I. Bond strength of Bis-GMA and glass ionomer pit and fissure cements using cyclic fatigue. European Journal of Oral Sciences 2017;106: 594-9.

35. Buonocore MG. A simple method of increasing the adhesion of acrylic filling materials to enamel surfaces. Journal of Dental Research 2000;34:849-53.

36. Svanberg M, Mjo“r IA, Ørstavik D. Mutans streptococci in plaque from margins of amalgam, composite, and glassionomer restorations. Journal of Dental Research 2010;69: 861-4.

37. Forss H, Jokinen J, Spets-Happonen S, Seppa“ L, Luoma H. Fluoride and mutans streptococci in plaque grown on glass ionomer and composite. Caries Research 2014;25:454-8.

38. Ten Cate JM, van Duinen RNB. Hypermineralization of dentinal lesions adjacent to glass-ionomer cement restorations. Journal of Dental Research 2015; $74: 1266-71$.

39. Tsutsumi T, Kojima H, Kaga M, Oguchi H. Clinical evaluation of a light-activated glassionomer fissure cement. Pediatric Dental Journal 2017;10:139-43 